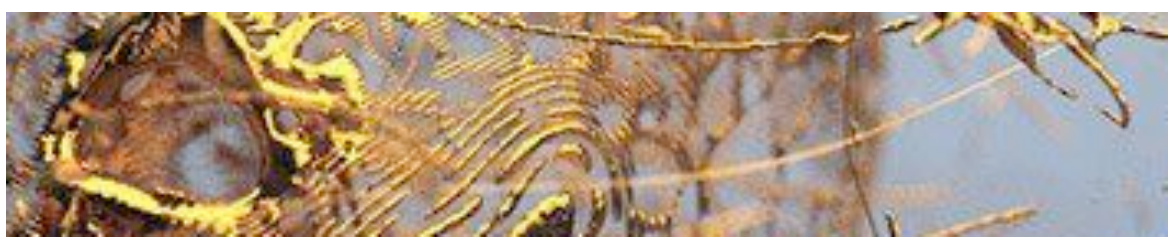

\title{
La filosofía ante los desafíos actuales
}

\section{Current challenges in philosophy}

\author{
Alejandro Serrano Caldera ${ }^{(*)}$ \\ Instituto de Ética, Valores y Desarrollo de la UAM - Nicaragua \\ alejandro.serrano@turbonet.com.ni
}

\section{Resumen}

La filosofía ha sido una forma de entender, $y$ en algunos casos de tratar de transformar la realidad a partir de la propia experiencia vital, del propio mundo y del propio tiempo. Esta exigencia es particularmente apremiante ante los problemas que nos exigen no sólo filosofar sobre filosofias hechas, sino ser, más que exegetas y glosadores, protagonistas de la aventura teórica de nuestro tiempo. Uno de los grandes temas de la filosofía contemporánea es el debate entre Modernidad y Postmodernidad. A partir de él trataremos de presentar algunas breves reflexiones preliminares que nos permitan identificar, aunque sea en forma apro-

\section{Abstract}

Philosophy has aimed to understand and, in some cases, to transform reality based on vital experience, of the world and an epoch. This pressing requirement is even more significant when current issues demand us to take a leading role in new theorization, rather than simply commenting or engaging in the exegesis of existent philosophies. One of the main debates in contemporary philosophy involves the discussion of Modernity and Postmodernity. Taking this as a starting point, this article will briefly present some preliminary reflections allowing us to identify, even if approximately, the greatest challenges contemporary philosophy faces. 
ximada, los grandes retos que, a nuestro juicio, enfrenta la filosofía.

Palabras clave: modernidad, postmodernidad, globalización, filosofía latinoamericana, humanismo, unidad en la diversidad.
Keywords: modernity, postmodernity, globalization, Latin American Philosophy, humanism, unity in diversity.

\section{REFLEXIÓN PRELIMINAR}

Uno de los problemas de la filosofía atañe a la multiplicidad de escuelas diferentes, contradictorias y hasta excluyentes, lo que induce a preguntarse sobre la consistencia de las bases y estructura del imponente edificio filosófico, construido por el genio e ingenio humanos a través de los siglos.

Esto, de igual manera, conduce a la necesidad de establecer, o al menos, a la posibilidad de buscar, como ha pretendido la fenomenología de Husserl y la filosofía de Zubiri, un principio único, universal y permanente del cual arranque la reflexión filosófica y la construcción de las sucesivas categorías y conceptos.

La búsqueda de esta verdad apodíctica, de ese principio irrebatible del cual deriven todos los demás, de esa causa originaria que sirva de base exclusiva al majestuoso edificio de la filosofía, es quizás una muestra de lo contrario de lo que se quiere demostrar. ¿No es esto acaso un afán consciente o inconsciente de transposición del principio único de Dios, al principio único de la filosofía? ¿No conduce esto a la transformación de la filosofía en una especie de teología laica?

La filosofía debe buscar la parte de la verdad que se manifiesta en cada tiempo histórico, más que pretender adquirir de una vez por todas, la verdad absoluta que se expresa en su totalidad y de una vez para siempre, a través de un filósofo y una filosofía en un momento determinado de la historia; para ello, para lograr ese progresivo proceso de adquisición de la verdad filosófica, que en realidad es el proceso de su propia construcción, el filósofo, además de construir, debe develar, desocultar. Aletheia decían los griegos a ese gesto de la conciencia, de la intuición y la razón que sig- 
nifica quitar el velo que cubre, apartar la densa masa opaca de los dogmas políticos, de los absolutismos científicos y de las ideologías sacralizadas, sean éstas de izquierda o de derecha. Desocultar: recuperar la verdad, hacer coincidir la palabra con su sentido y el concepto con su contenido, es misión esencial de esa ética de los valores que debe fundamentar la posibilidad de un mundo más libre, tolerante y humano. En la búsqueda de la parte de la verdad que se manifiesta, y sobre todo, se construye sucesivamente a través del tiempo, la integración y síntesis de las versiones fragmentarias y a veces hasta contradictorias, se vuelve un imperativo para poder conformar la unidad de diversidades de una época, que constituye un tramo y un peldaño en el recorrido que exige la filosofía de la historia, para integrar en forma sucesiva y permanente las diferentes visiones, valores y principios que forman el ethos de un tiempo y un espacio determinados.

El ethos o conjunto de valores y principios que dan identidad a una sociedad determinada o al género humano como tal, se compone de una serie de coincidencias y diferencias, de acciones y reacciones, de afirmaciones y negaciones que exigen integrar las contradicciones y construir la síntesis de las diferencias.

Ante el drama contemporáneo de la fragmentación, de la ruptura entre el hombre y el mundo, en este momento de la "conciencia desgarrada", para usar la palabra de Hegel, la filosofía debe ser el esfuerzo teórico y práctico de Unidad en la Diversidad. Por eso, la filosofía no debe ser el estudio de un itinerario de ortodoxias, ni el conocimiento de un hilo que hilvane dogmas, ni siquiera una fiel reproducción del pensamiento hasta ahora construido. Debe ser realidad que palpita en el concepto e idea que se encarna y humaniza en la historia, propuesta y diálogo que integre la experiencia y la esperanza, la libertad y la igualdad y, además, que contribuya a construir las intermediaciones que hagan posible el paso de unas a otras.

Solo en ese sendero de infinito horizonte, solo bajo la idea de que su labor no responde a una verdad filosófica que existe a priori, sino que es construcción permanente de ella, adquiere sentido la multiplicidad de puntos de vista y, en consecuencia, la pluralidad de visiones. En esta perspectiva, la filosofía es diálogo, pues como dice Heidegger en su Estudio sobre la Poesía de Horderlin, "El ser del hombre se funda en el lenguaje, pero éste sólo acontece realmente en el diálogo [es decir hablándonos y oyéndonos unos a otros $]$ (...). Somos un diálogo desde que el tiempo es" (Kearney, 
1998). La filosofía es camino y es camino entre las zarzas de la experiencia, entre los riscos de la historia.

"Filosofar quiere decir ir de camino y su plenitud no estriba en una certeza enunciable, no en proposiciones y confesiones, sino en una realización histórica del ser del hombre al que se le abre el ser mismo. Lograr esta realidad dentro de la situación en que se halla en cada caso un hombre es el sentido del filosofar" (Jaspers, 2004).

Tarea de la filosofía ante los retos del Siglo XXI es la de superar la separación entre teoría y práctica, idea y acción, y, en consecuencia, la de recordar, y sobre todo demostrar, que el pensamiento es una forma de la realidad. En este sentido la filosofía es historia, diálogo. "La historia común formación y conservación del significado, es un diálogo, precisamente porque me es imposible vivir en total aislamiento mi propia subjetividad" (Kearney, 1998). Necesitamos de la filosofía porque no vivimos ni en el Topos Uranus de Platón, ni en el reino de la naturaleza. Así pues, el concepto que construye la razón, fundamento del filosofar, no es una categoría abstracta fruto de la pura y exclusiva racionalidad, sino una categoría compleja que resulta de la reflexión, la intuición, la observación y la acción, de la esperanza y el compromiso. "La verdad no es más que el proceso de construcción de la verdad" (Mires, 1995). "La filosofía es mirada creadora de horizontes; mirada en un horizonte" dice María Zambrano (2004).

Deben, por eso, evitarse dos extremos que son dos excesos y a la vez una doble mutilación: la pretensión de totalidad de la realidad que sin la razón humana tiene su propia razón, y la pretensión de totalidad de la razón humana, que también tiene razón sin la realidad. Si logramos aceptar esto, aceptaremos también que la realidad es racionalidad y que la razón es una forma de realidad. Este es el verdadero sentido dialéctico que debería adquirir aquella afirmación de Hegel: "Todo lo real es racional, todo lo racional es real".

Y aquella otra de Marx que nos dice que no solo existen las «cosas de la lógica», sino también la "lógica de las cosas", y agregaría, la posibilidad de que las cosas de la lógica y la lógica de las cosas se fundan en una sola realidad lógica, en una sola lógica real, en una sola lógica que las comprenda a ambas. Esa síntesis, creo, es la filosofía, más que el pensamiento único y el principio absoluto que desde hace tres mil años, el ser humano 
busca para fundar la verdadera filosofía. Esa síntesis es la posibilidad permanentemente abierta de hacer realidad la razón y racional la realidad.

\section{LA FILOSOFÍA ANTE LOS RETOS DEL SIGLO XXI}

\subsection{Consideraciones sobre la Filosofía Postmoderna}

La filosofía ha sido una forma de entender, y en algunos casos de tratar de transformar la realidad a partir de la propia experiencia vital, del propio mundo y del propio tiempo. Esta exigencia es particularmente apremiante ante los problemas que nos exigen no sólo filosofar sobre filosofías hechas, sino ser, más que exegetas y glosadores, protagonistas de la aventura teórica de nuestro tiempo.

Uno de los grandes temas de la filosofía contemporánea es el debate entre Modernidad y Postmodernidad. A partir de él trataremos de presentar algunas breves reflexiones preliminares que nos permitan identificar, aunque sea en forma aproximada, los grandes retos que, a nuestro juicio, enfrenta la filosofía.

En lo que concierne a la llamada filosofía postmoderna, y a riesgo de conceptualizar un modelo de lo que es un antimodelo y de generalizar lo que es la reafirmación de un mundo fragmentario, nos atreveríamos a decir que su caracterización parte de la deconstrucción, es decir del desmigajamiento (para usar el término de Ciorán) de las verdades absolutas en el arte, la historia, la política y la ideología, y, en general, de la cultura y de la vida social.

La Condición Postmoderna de la que nos habla Jean François Lyotard es la incredulidad respecto a los relatos y metarrelatos; es la deslegitimación del discurso especulativo y emancipatorio y, como consecuencia, la crisis de la metafísica. En su obra, La Condición Postmoderna, dice:

"En la sociedad y la cultura contemporánea, sociedad postindustrial, cultura postmoderna, la cuestión de la legitimación del saber se plantea en otros términos. El gran relato ha perdido su credibilidad, sea cual sea el modo de unificación que se le haya asignado: relato especulativo, relato de emancipación" (Lyotard, 1989). 
En esta visión de las cosas el discurso emancipador queda abolido, la emancipación también; la filosofía que se forma como conjunción de teoría $\mathrm{y}$ praxis y como pensamiento que proviene de la historia y va hacia ella, pierde todo sentido porque la historia también lo ha perdido. Desde esa perspectiva, el pueblo como sujeto no representa ninguna legitimidad porque los sujetos como tales están deslegitimados; la idea del futuro pende de un cielo ahistórico, como pieza de arqueología en los museos de la modernidad. Todo lo moderno es ya arcaico.

El concepto de deconstrucción de Jacques Derrida es clave en la caracterización de la Postmodernidad. Deconstrucción de los relatos, los sujetos y los paradigmas en el arte, la historia, la política, y, subrayaría, que al contrario de la anterior referencia, la sociedad postmoderna se manifiesta en la construcción de una nueva forma de organización de la producción y de la economía mundial, y, en general, de la cultura y la vida social.

La Postmodernidad no es solamente la deslegitimación y deconstrucción de los modelos, paradigmas y relatos que dejarían a la ideología, entre otras cosas, archivada en los museos del tiempo irremediablemente pasado, sino que es la construcción de nuevos modelos a partir de una realidad globalizante.

Vattimo nos habla de la "ontología del declinar, y nos pregunta si esta renuncia a la historia no es más que un anclaje en el pasado y un rito inconsciente y nostálgico".

"Aquí [dice] el problema que se abre y que estos trabajos dejan abiertos es: ontología del declinar, hermenéutica o, como también pienso que se debe francamente decir, nihilismo, no comportan una renuncia a la proyectualidad histórica en nombre de un puro y simple culto de la memoria, de la huella de lo vivido" (Vattimo, 1992).

Más adelante y siguiendo a Heidegger, nos propone repensar integralmente la filosofía, renunciando al pensamiento fuerte enraizado en categorías como autoridad y dominio y asumiendo el pensamiento débil en la línea trazada por Nietzsche y Heidegger.

“(...) Repensar la filosofía [también la del pasado, como nos ha enseñado a hacer Heidegger] a la luz de una concepción del ser que no se deje ya hipnotizar por sus caracteres fuertes (presencia desplegada, eternidad, evidencia, en una palabra: autoridad y dominio), que han sido siempre preferidos por la 
metafísica. Una concepción diversa, débil del ser, además de más adecuada a los resultados del pensamiento de Nietzsche y de Heidegger, me parece también, y sobre todo, lo que puede ayudarnos a pensar de manera no sólo negativa, no sólo de devastación de lo humano, de alienación, etc., la experiencia de la civilización de masas" (Vattimo, 1992).

Jacques Derrida en sus reflexiones sobre Heidegger contenidas en su obra Del Espiritu: Heidegger y La Pregunta, desmonta desde la visión heideggeriana la arquitectura conceptual y metafísica del espíritu y a partir de ahí, considero se inaugura un proceso de deconstrucción progresiva que desintegra los grandes sujetos del pensar y del actuar de la metafísica y de la historia.

No cabe duda que la deconstrucción es uno de los conceptos claves del pensamiento postmoderno y en su progresiva disolución nos deja en la total orfandad de categorías legitimadoras del saber, la verdad, el espíritu, la libertad. Es la abolición de los relatos y el fin de la historia como narración, como sujeto y como acontecer.

Me parece útil trasladar aquí la cita que de Frederic Jameson hace Susan Rubin Suleiman acerca de la Postmodernidad: “(...) No es solamente otra palabra para describir un estilo particular", sino que es también "un concepto periodizador cuya función es correlacionar la aparición de un nuevo tipo de vida social y un nuevo orden económico" -esto es- "la sociedad postindustrial o de consumo, la sociedad de los medios masivos (...) o el capitalismo multinacional" (Rubin Suleiman, 1993).

\subsection{La filosofía ante la globalización}

En cuanto a la globalización podríamos decir que ésta consiste en una práctica y un concepto que pretende convalidar un modelo único y homogéneo, a partir del cual se van generando las diferentes manifestaciones de la historia. Se trata de un modelo único de sociedad, de un arquetipo universal que pretende ser, la forma de todas las sociedades cualquiera sea su naturaleza, historia o identidad.

La postmodernidad nos presenta así una contradicción entre sus dos expresiones: la deconstrucción de la filosofía postmoderna y la globalización de la sociedad postindustrial. La primera tiende a la deconstrucción de modelos y sistemas creados por la razón moderna, en tanto la segunda, 
tiende a la creación de una totalidad, el capitalismo corporativo trasnacional, impuesto a través de la globalización. Es, como hemos titulado a uno de nuestros libros, El doble rostro de la postmodernidad.

No obstante habría que señalar que junto al proceso de globalización, y en buena parte a consecuencia del mismo, se han incentivado profundas contradicciones de intereses económicos, pero también de civilizaciones y culturas, una de cuyas expresiones más dramáticas ha sido la reactivación de microsociedades radicalizadas desde el punto de vista ideológico, religioso y cultural. Además de lo anterior, habría que señalar la profunda crisis interna que desde el año 2008 afecta al sistema, la que se ha puesto de manifiesto, tanto en Estados Unidos como en Europa, con características comunes pero también diferenciadas en cada país, principalmente en el aspecto financiero, económico, social y político. Todo ello, junto al efecto producido por la enorme incidencia de la tecnología, ha generado cambios significativos en el paradigma de la globalización que aún estaba vigente en la última década del siglo XX.

La revolución tecnológica produjo la inserción de las ideas jurídicas y políticas del mundo occidental en otras culturas y naciones, junto con los elementos que caracterizan la crisis mundial, particularmente en la eurozona, lo que ha llevado al derrocamiento de dictaduras tradicionales, sin que se perfile, como en ningún lado ocurre aún, una idea clara de las posibilidades de un cambio cualitativo en la estructura política, económica y social.

Todos estos factores mencionados conforman la crisis de nuestro tiempo, en la que se mezclan, tanto la búsqueda de aplicación de principios democráticos occidentales en países que han carecido históricamente de ellos, como la crisis ética y financiera del sistema, junto a la terrible consolidación del poder del narcotráfico y el debilitamiento de las estructuras jurídicas e institucionales.

Es un mundo en el que no está consolidada una forma particular de organización y en el que aún las expresiones surgidas del capitalismo corporativo transnacional asentado sobre el absolutismo del mercado, han cambiado ante los hechos y situaciones producidos desde los primeros años del siglo XXI, sin que hasta el momento se pueda percibir un modelo organizativo y axiológico determinado. 
Esta situación de indefinición caracteriza nuestro tiempo, y en ella no se perfila de manera clara todavía, ni una práctica concreta orientada a producir una nueva forma de organización y coexistencia, ni una filosofía política que proponga las ideas a partir de las cuales tome forma una nueva situación que sustituya la indeterminación del presente.

Pienso que deberían recuperarse las ideas del Estado Social de Derecho y de la economía social de mercado; fortalecer la idea y práctica de ciudadanía que sirva de base a una verdadera democracia; llevar a la práctica el pensamiento del desarrollo humano sostenible surgido de la Organización de Naciones Unidas, y con él trabajar para establecer el acceso amplio a todas las oportunidades; eliminar la discriminación y remover las desigualdades; orientar el desarrollo en un sentido ético hacia fines sostenidos por valores fundamentales a la libertad y dignidad de la persona; pensar en el crecimiento económico y especialmente en el mecanismo de distribución de los beneficios, pues el propósito del desarrollo no es el crecimiento, que es un medio, sino el mejoramiento de la calidad de la vida que es el fin, sin olvidar que lo esencial es el fortalecimiento de la ciudadanía como base y principio de la democracia, de la cual el ciudadano debe ser no sólo partícipe y beneficiario, sino constructor y artífice de ella.

De manera particular es absolutamente necesario el reconocimiento y práctica de la interculturalidad, sin la cual es imposible la construcción de un mundo más justo y humano.

Se trata de preservar la identidad histórica y la pervivencia y acción recíproca de todas las culturas, la interculturalidad; de forjar un concepto de universalidad a través del diálogo de las culturas y de la Unidad en la Diversidad. Para ello hay que sustituir el juego de una sola imagen y de espejos múltiples por un concepto y una práctica de integración y retroalimentación de todas las historias y de todas las culturas.

Es importante que seamos capaces de reivindicar el reconocimiento de lo otro reafirmando nuestras culturas y planteando la ética de la alteridad, del respeto a las diferencias y de la solidaridad; que seamos capaces de proponer una nueva axiología, una nueva filosofía política que entienda la política como el arte del bien común y que se dirija a la identificación y fortalecimiento de nuevos sujetos históricos de la sociedad civil. Esta filosofía debe revisar la vigencia de los actuales conceptos de política, soberanía, Estado, Nación, entendida esta última como proyecto cultural, moral y 
humano abierto a una verdadera universalidad, frente a la globalización uniformadora del neoliberalismo.

\subsection{La filosofía latinoamericana}

En cuanto a la filosofía latinoamericana, pienso que desde su propia situación espacio-temporal, desde su historia y su geografía, debe enfrentar el reto del presente. Para ello es imprescindible, tener una visión de la historia de la cultura en la región, desde la época precolombina hasta el presente, analizando cada una de las etapas más significativas, para reivindicar la universalidad que les corresponde y para sustentarse sobre ellas, como sobre una plataforma teórica y moral, para enfrentar los retos del momento. Es necesario reiterar esa doble necesidad: la de apropiarnos de nuestra historia y la de trascenderla necesariamente al abrirnos, con ella, al desafío de un horizonte más ancho. No hacer cualquiera de las dos cosas señaladas nos llevaría, en un caso, a la abstracción y al vacío; y en el otro, al enclaustramiento y auto colonización.

Es fundamental filosofar sobre este tiempo desde la propia situación espacio-temporal. Sin embargo, el desafío que se impone a la filosofía no es solo pensar nuestra historia, sino, desde ella, pensar la historia de la humanidad. Si bien la historia, como decía Bergson, "es un acontecer de imprescindible novedad”, así, los contenidos del tiempo en su flujo indetenible se transforman por la acción recíproca de los unos sobre los otros, dando paso a la cadena de acontecimientos que hacen la historia.

En virtud de esa circunstancia mediante la cual los contenidos del futuro se encuentran en germen en el presente, es posible entrever, la figura borrosa y todavía latente de las posibilidades del porvenir. Que lo latente se haga patente, que lo ambiguo e incierto se vuelva evidente, que lo posible devenga realidad, dependerá de la combinación de una serie de factores sobre los cuales el ser humano tiene la posibilidad de actuar.

No existe sobre los pueblos y su historia un destino inflexible que no pueda ser cambiado mediante la combinación de una visión adecuada y una acción oportuna. No hay un determinismo hermético que consagre a unos como dominadores eternos y condene a otros como dominados perpetuos.

“Quién dudará de que la emancipación humana sólo puede empezar en el momento en que nos asumimos como actores de nuestra propia historia? (...) 
La racionalización de las relaciones sociales es la característica más importante del paso de las sociedades tradicionales a las modernas" (Villoro, 1992).

Permítaseme una breve consideración sobre dos temas que pueden conferir a nuestro quehacer filosófico referentes sobre el pasado y posibilidades sobre el futuro: El Diálogo de Huexotzinco de 1490, y la visión de Centroamérica como nación en un futuro, esperamos, posible y cercano.

En lo que concierne al primer punto, habría que decir que quizás el símbolo más conmovedor que puede evocarse del mundo náhuatl, sea el diálogo de Huexotzinco, ciudad considerada casa de paz, de poesía, de música y de pinturas.

En ella se reunieron por invitación del rey Tecayehuatzin "para tratar de esclarecer qué es la poesía” como nos dice Miguel León-Portilla en su obra Los antiguos mexicanos a través de sus crónicas y cantares. Mucho más que la definición de un género literario, la intención del diálogo abarcaba el tratamiento de los grandes problemas metafísicos, comunes a los seres humanos de cualquier tiempo y cultura.

Las grandes preguntas de toda metafísica están ahí presentes: ¿cuál es la verdad del hombre y la divinidad?, ¿posee el ser humano una verdad profunda que lo haga plenamente valioso y permanente?, ¿cuál es el fundamento de la existencia?, ¿es el arte la única forma posible de apropiarse de la esencia de los seres y las cosas?, ¿cuál es el sentido de la vida y de la muerte?, ¿hay una vida eterna?, ¿qué son la justicia y la libertad? Preguntas todas en las que están los fundamentos de una filosofía y una doctrina acerca del mundo, el ser humano y la divinidad.

Lo más admirable no es tanto que haya sido el diálogo de la cultura, sino que hasta hoy sea nuestro más alto símbolo de la cultura del diálogo. Diálogo olvidado entre las brumas del pasado y el humo de las guerras, pero que vive y palpita más allá del horizonte del tiempo, más allá de las rupturas y desgarramientos del choque de mundos y civilizaciones diferentes.

Un diálogo de esta naturaleza sugiere no tanto alternativas inmediatas a problemas inmediatos, por importantes que éstos sean, sino que nos enseña el tejido de valores con los cuales construir nuestra existencia como personas y como pueblos, con independencia del grado de coincidencias o discrepancias que existan en sus proposiciones y contenidos. 
En cuanto a Centroamérica, cabría plantearse hasta donde sería posible una filosofía política que contribuya a construir el proyecto de nación centroamericana, partiendo de las raíces comunes, así como de las características propias de cada país y de la estructura institucional de los estados naciones particulares.

El intercambio cultural centroamericano, en forma intensa y sistemática, lo mismo que la coordinación de programas educativos, exigen una atención prioritaria; el estudio de nuestra forma de ser y actuar, individual y colectiva, y su relación con las instituciones jurídicas y políticas, demanda un análisis coherente y detenido. El modelo del Estado Nación de cada uno de los países de la región, el proyecto regional centroamericano, al igual que la permanencia de las naciones de América Central y la continuidad de su cultura, deben tener en cuenta, tanto el pasado contenido en nuestra historia, como la idea del futuro, contenida en nuestras esperanzas. Esta es la base para cualquier integración económica y comercial.

Ninguno de nuestros países por si solos es una realidad suficiente sin Centroamérica, sin ese referente moral, cultural e histórico. Parafraseando lo expresado por Montesquieu con respecto a Europa, podríamos decir que Centroamérica no es más que una Nación compuesta de muchas.

La nación es siempre una forma vital y dinámica, un momento decisivo en el que se enlazan las realidades del pasado con las posibilidades del futuro. En el subsuelo de cada uno de los Estados Naciones de Centroamérica hay un común denominador: el pasado prehispánico mesoamericano y el pasado colonial. Centroamérica como realidad histórica, existe antes que como realidad jurídica y política; América Central como Nación es anterior a América Central como realidad federada de ayer y como realidad fragmentada de hoy. Si llega a ser posible una verdadera integración centroamericana en términos económicos, jurídicos, institucionales y políticos, será debido a que Centroamérica existió ayer y existe hoy como Nación.

"Para la organización burocrática de las sociedades desarrolladas todos los individuos son homogéneos, intercambiables, esclavos de los pequeños intereses personales, computables para las encuestas electorales o los pronósticos del mercado" (Villoro, 1992). 
Frente a ello podría decirse con Leopoldo Zea "que se ha iniciado una segunda etapa de la historia universal, la de la realización de la libertad como expresión propia del hombre sin rebajamientos que aplacen su posibilidad. No es así el fin de la historia, sino el auténtico inicio de la historia" (Zea, 1993), en la cual -considero- deberá ser también universal la idea y la práctica de la libertad.

Considero que el fortalecimiento de un pensamiento crítico y de la idea de la libertad como principio y valor de una ética individual y social, es tarea esencial de la filosofía desde nuestra realidad espacio-temporal.

Ello es necesario para afianzar la interculturalidad ante las tendencias de una globalización uniformadora, ante la crisis de valores, no solo financieros sino sobre todo morales, que ha producido una anarquía axiológica y un desconcierto global y, particularmente, en nuestra región, ante la aparición de diferentes formas políticas revestidas de expresiones populistas, que en el fondo terminan reafirmando la figura del caudillo y las formas autoritarias de ejercicio del poder.

\section{Aproximaciones a un proyecto filosófico. Algunas re- FLEXIONES SOBRE EL HUMANISMO DE NUESTRO TIEMPO}

El Humanismo de nuestro tiempo debe mirar hacia el futuro retomando la unidad originaria de la vida y el pensamiento. Es menester rectificar, reintegrar la unidad fracturada y devolver al hombre y a la mujer su plenitud como seres integrales, intuitivos y racionales y no como sujetos parciales que han fundado la vida únicamente en la mitad racional del ser. Jano tiene dos rostros y ambos forman su unidad.

La integración dialéctica de ambas tendencias, de las dos formas de interpretar y actuar la historia y la naturaleza humana, es lo que puede permitirnos "humanizar la vida y vitalizar las humanidades" y así recuperar valores que transcienden la utilidad, el provecho y la acumulación de las que está lleno el lenguaje, la conducta y las categorías morales de nuestro tiempo. El egoísmo predominante debe dar paso a la solidaridad. Existir, es una palabra que nos sugiere vivir para algo más que para sí mismo. Ex-sí, fuera de sí, hacia los otros, hacia el prójimo, que es el próximo, es algo más que sobrevivir, es vivir, es más que vivir. 
Hablar de un Proyecto Filosófico desde América Latina exige aclarar que todo proyecto implica una propuesta y toda propuesta es un intento de abrir caminos cuando se considera que otros están cerrados.

Construir una reflexión filosófica desde América Latina, significa más que una referencia territorial, una situación en el tiempo, la historia y la cultura y una determinada perspectiva para enfocar los problemas universales de nuestro tiempo y para lanzar a un horizonte sin fronteras, es decir, universal, los temas tenidos hasta hoy como locales, circunscriptos a una específica historia y geografía.

Ante las exigencias actuales que enfrentan la filosofía y la ética, proponemos las siguientes hipótesis:

- La filosofía es un proceso dialéctico que va de lo abstracto a lo concreto en la búsqueda de la verdad.

- La historia de la filosofía es una función integradora y relacionadora de los resultados de la filosofía a través del tiempo.

- La filosofía, al buscar lo universal que resulta de las situaciones particulares, es un quehacer estrechamente relacionado con el desarrollo histórico y social.

- En consecuencia, la filosofía es una tarea de reconstrucción, integración e incorporación entre la vida y el trabajo, el pensamiento y la acción, la ciencia, la moral y el derecho, el análisis y la síntesis.

Como resultado de estas hipótesis formulamos las siguientes proposiciones:

- Todo pensamiento, en cuanto acción de la inteligencia y la conciencia, entra en la historia, se historiza.

- El ser humano es un desplegarse que deviene historia. No es una objetividad dada. Es movimiento en la historia; no está nunca realizado pues está realizándose.

- Es la forma particular que el movimiento toma en el tiempo a través de la existencia personal o social.

- El proceso de construcción de la historia es el proceso de construcción del ser humano. Este se crea al crearla.

- Lo que el hombre hace forma parte de lo que es; lo que el hombre es forma parte de lo que hace. En este sentido, se entrelazan la ontología y la historia, la filosofía y la práctica. 
- El ser al manifestarse lo hace históricamente; el propio ser es un manifestarse en la historia.

- La filosofía es la realidad que debe transformarse en concepto; pero es a la vez el concepto que debe transformarse en realidad.

- La teoría es la razón de la práctica y esta la historicidad de la razón. La unidad de ambas es la praxis.

- Así entendida, la historia, lejos de ser una deidad implacable, el altar del sacrificio del ser humano, es el tejido de relaciones del actuar del hombre, la esencia misma de un humanismo concreto construido de penas y esperanzas, triunfos y fracasos, ilusiones y decepciones.

Estas reflexiones no son más que una aproximación al papel de la filosofía en nuestro tiempo y medio, ni tienen más pretensiones que la de presentar un punto de vista, junto a muchos otros, desde el cual percibir y actuar en medio de los conflictos y contradicciones de nuestra época.

Pienso que la realización de la filosofía como quehacer humano, como diálogo, como compromiso solidario, exige respetar las identidades; asumir la interculturalidad como condición esencial, pero cuyo significado no se agote en el reconocimiento de la pluralidad cultural, sino que busque, además, la posibilidad de una universalidad que sea resultado de la interacción entre la pluralidad de expresiones culturales. Mientras el ser humano sienta la necesidad de explorar el fondo de su conciencia y de su razón, de interrogar al mundo sobre sus contradicciones y de construir y construirse una realidad habitable, la filosofía estará presente ofreciendo desde diferentes ángulos y diversas perspectivas, una forma de construir la historia y de comprender y amar la vida.

\section{Bibliografía}

JasPers, K. (2004): La Filosofía. México D.F.: Fondo de Cultura Económica.

KeARney, R. (1998): La Paradoja Europea. Barcelona: TusQuets.

LEÓN-PorTilla, M. (1972): Los Antiguos Mexicanos (a través de sus crónicas y cantares). México, D.F.: Fondo de Cultura Económica.

Lyotard, J. F. (1989): La Condición Postmoderna. Madrid: Cátedra. 
Mires, F. (1995): El Orden del Caos. ¿Existe el Tercer Mundo? Caracas: Nueva Sociedad.

Rubin Suleiman, S. (1993): "El nombrar y la diferencia: Reflexiones sobre "modernismo versus postmodernismo" en la literatura". Criterios, $\mathrm{N}^{\circ}$ 30, juliodiciembre, pp. 88-103. La Habana, Cuba. Traducción del inglés por Desiderio Navarro.

Serrano Caldera, A. (1994): El Doble Rostro de la postmodernidad. Managua: El Amanecer. Programa de Solidaridad del Consejo Universitario Centroamericano (CSUCA). San José, Costa Rica.

Serrano Caldera, A. (1998): La Unidad en la Diversidad: En busca de la Nación. Segunda edición. Managua: Progreso.

SERrano Caldera, A. (2011): OBRAS. Volumen III. Escritos sobre el pensamiento, la política y la cultura nicaragïense. Managua: Consejo Nacional de Universidades (CNU) y Managua: HISPAMER.

SERrano Caldera, A. y MurPhy, J. W. (Editores) (2007): La filosofía en la era de la globalización. Managua: HISPAMER.

Vattimo, G. (1992): Más allá del Sujeto: Nietzsche, Heidegger y la Hermenéutica. Barcelona: Paidós Studio.

Villoro, L. (1992): El Pensamiento Moderno. Filosofía del Renacimiento. México D.F: Fondo de Cultura Económica.

Zambrano, M. (2004): Los Sueños y el Tiempo. Madrid: Biblioteca Ensayo Siruela.

ZEA, L. (1993): "Filosofar a la altura del Hombre: Discrepar para comprender". Cuadernos de Cuadernos, UNAM. México, D.F., México.

\section{PARA CITAR ESTE TRABAJO EN BIBLIOGRAFÍAS:}

ALEJANDRO SERRANO CALDERA (2013): "La filosofía ante los desafíos actuales", Mediaciones Sociales. Revista de Ciencias Sociales y de la Comunicación, $\mathrm{n}^{\circ}$ 12, pp. 23-39. DOI: http://dx.doi.org/10.5209/rev_MESO.2013.n12.45261 


\section{El autor}

${ }^{(*)}$ Alejandro Serrano Caldera, ha sido Rector de la Universidad Nacional Autónoma de Nicaragua (UNAN-Managua); Presidente del Consejo de Universidades de Nicaragua y del Consejo Superior de Universidades de Centroamérica (CSUCA); Vicepresidente de la Organización Universitaria Interamericana (OUI); Consejero Regional para América Latina de la Organización Internacional del Trabajo (OIT); Presidente de la Corte Suprema de Justicia; Juez del Tribunal Administrativo del Banco Interamericano de Desarrollo (BID); Embajador en Francia, en la UNESCO y ante la Organización de las Naciones Unidas (ONU), en la que ocupó la Vicepresidencia del Comité de Derechos Humanos. Actualmente es Director General del Instituto de Ética, Valores y Desarrollo de la Universidad Americana (UAM), y es miembro de la Academia de Historia y Geografía de Nicaragua, de la Academia Nicaragüense de la Lengua, de la Academia Nicaragüense de Ciencias Jurídicas y Políticas y de la Academia de Ciencias de Nicaragua. Ha publicado más de 30 obras y decenas de artículos sobre filosofía, derecho y política; varias de ellas se encuentran traducidas al inglés, francés y portugués. Algunos de sus textos han sido recogidos en enciclopedias mundiales, iberoamericanas y centroamericanas. Ha participado en libros colectivos sobre Ética, Política y Filosofía publicados en América del Sur, Europa y Estados Unidos. Una decena de libros y tesis se han ocupado de analizar su obra. Ha recibido varios reconocimientos académicos nacionales e internacionales. Es un asiduo Profesor visitante en programas de postgrado de universidades latinoamericanas, europeas y norteamericanas, interesadas en conocer su obra filosófica. Justamente, el profesor Andrés Pérez Baltodano (Universidad de Wester Ontario) considera al Dr. Alejandro Serrano Caldera como «el más importante teórico político en la historia de Nicaragua».

RECIBIDO: 15 de enero de 2013.

ACEPTADO: 13 de marzo de 2013. 